\title{
Pacifier use modifies the association between breastfeeding and malocclusion: a cross-sectional study
}

\section{Catiara Terra da COSTA ${ }^{(a)}$ Ayah Qassem SHQAIR(a) Marina Sousa AZEVEDO(a) Marília Leão GOETTEMS(a) Maria Laura Menezes BONOW(a) Ana Regina ROMANO(a)}

(a) Universidade Federal de Pelotas - UFPel, School of Dentistry, Post-Graduate Program in Dentistry, Pelotas, RS, Brazil.
Declaration of Interest: The authors certify that they have no commercial or associative interest that represents a conflict of interest in connection with the manuscript.

\section{Corresponding Author:}

Marília Leão Goettems

E-mail:mariliagoettems@hotmail.com

https://doi.org/10.1590/1807-3107bor-2018.vol32.0101

Submitted: January 17, 2018

Accepted for publication: July 24, 2018

Last revision: August 23, 2018

\begin{abstract}
This study aimed to evaluate the influence of breastfeeding and pacifier use on the occlusal status of preschool children. A crosssectional study was conducted with children $(n=489)$ aged 2-5 years in private and public schools in Pelotas, South Brazil. Mothers answered a questionnaire on demographic, socioeconomic and behavioral variables, including breastfeeding and non-nutritive sucking habits. Malocclusion was classified as normal/mild and moderate/severe, according to WHO criteria. The association between breastfeeding and pacifier use with malocclusion was tested using multivariate logistic regression. The prevalence of malocclusion was 37.83\% (95\%CI 33.5242.14 ), and $57.87 \%$ of the children used a pacifier. A total of $46.01 \%$ of the sample was exclusively breastfed for 6 months, and 24.74\% were never breastfed. Malocclusion was associated with pacifier use, and with both non-exclusively breastfed and never breastfed. After adjustments for demographic and socioeconomic variables, the children who used a pacifier and were never breastfed (OR $=19.08$; 95\%CI 8.54-42.63), or who used a pacifier and were not exclusively breastfed (OR $=13.74$; 95\%CI 6.1130.92), showed worse occlusal conditions, compared with the children who were exclusively breastfed and never used a pacifier. Pacifier use modifies the relationship between breastfeeding and occlusal status.
\end{abstract}

Keywords: Malocclusion; Tooth, Deciduous; Breast Feeding.

\section{Introduction}

A pacifier is considered a non-nutritive sucking habit, defined as an object that a baby is given to suck so that the baby feels comforted and stays quiet. ${ }^{1}$ The conventional pacifier has a nipple with a cherry-like shape, but there are also physiologic pacifiers (orthodontic) that are designed to better fit the child's oral structures, and that have existed for over 60 years. Pacifier use is associated with a reduced incidence of sudden infant death syndrome, although the exact mechanism of the effect is not well understood. ${ }^{2}$ Conversely, there is evidence confirming that the use of a pacifier can lead to negative outcomes, such as reduction of breast milk production, ${ }^{3}$ shortened duration of breastfeeding, ${ }^{4,5}$ infection, and also dental malocclusion. ${ }^{6}$

In the deciduous dentition, occlusion has been found to be influenced by harmful habits during early childhood, ${ }^{4}$ such as non-nutritive sucking habits (pacifier use and finger sucking), bottle-feeding and 
early weaning. ${ }^{6,78}$ Generally, health professionals reinforce the importance of breastfeeding, and advise parents against pacifier use and the establishing of good feeding habits, but always take into account special individual circumstances. ${ }^{1}$ Thus, the more knowledgeable the health professional about the consequences of pacifier use, the better they can advise parents.

This study aimed to assess the association of breastfeeding and pacifier use with malocclusion in preschool children, adjusting for maternal and child demographic and socioeconomic factors. The hypothesis of the study was that children who were breastfed would present a lower prevalence of malocclusion, whereas children who used a pacifier would present a higher prevalence. Moreover, it was hypothesized that pacifier use would modify the association between breastfeeding and malocclusion.

\section{Methodology}

Design

A school-based observational cross-sectional study was performed to assess the oral health status of children aged two to five years old. ${ }^{9}$

\section{Setting}

The study comprised children enrolled in preschools in the municipality of Pelotas, Brazil, in 2007.

\section{Sample}

The Epi-Info 6.0 Program was used to calculate the minimum sample size required, considering a $50 \%$ prevalence of malocclusion in the deciduous dentition, an acceptable error of five percentage points, and a confidence level of $95 \%$. We added $10 \%$ to cover any losses and refusals, and 15\% to allow stratified analysis, totaling 387 children. The sample effectively studied was greater than that calculated, in view of our interest in studying other outcomes. Thus, the final sample size was 502 children.

A list of preschools was provided by City Hall. A total of 36 private and 24 public preschools existed in the city at the time of data collection. In order to ensure variability among the characteristics and considering the fieldwork logistics, one third of each type of school was selected, thus ensuring the proportionality of schools existing in the city (twelve private and eight public schools). All children aged two to five years old, with complete deciduous dentition, with no permanent teeth, and with no orthodontic treatment, as well as those with prior permission from the responsible persons, were included. The visits were scheduled after the parents returned the authorization.

\section{Data collection}

Three work teams were formed to collect the data. Each was made up of one examiner (a master's student in Pediatric Dentistry), and one annotator (a graduate student in dentistry), and included other graduate students in charge of organizing the flow of children during oral clinical exams.

\section{Measurements}

A previously tested questionnaire was sent to the children's parents to collect information regarding breastfeeding practices, containing the following categories: exclusive breastfeeding for 6 months or more (providing human milk without introducing any other foods or drinks to the child until 6 months of age); non-exclusive breastfeeding (introduction of other sources of feeding before 6 months); and never breastfed. The item, pacifier use, was dichotomized as never used or used. Data on the following demographic variables were also collected: child age and gender, mother's age; socioeconomic variables: family income (categorized in tertiles), and mother's education $(>8$ years or $\leq 8$ years of study).

The index recommended by the World Health Organization was used to evaluate the prevalence of malocclusion. ${ }^{10}$ It classifies occlusion into three categories: no malocclusion (absence of any alteration), mild occlusion (one or more teeth with rotation or slight crowding or spacing that impair regular alignment), and moderate/severe occlusion (unsightly effect on facial aesthetics, significant reduction in mastication, or phonetic problems caused by one or more of the following conditions affecting the four incisors: overjet $>9 \mathrm{~mm}$; anterior crossbite equal to or greater than the size of a tooth; open bite; median line deviation estimated at $4 \mathrm{~mm}$ or more; and crowding or spacing estimated at $4 \mathrm{~mm}$ or more). ${ }^{11}$ 
In order to minimize the variations and increase accuracy and reliability, the three dentists who performed the clinical oral examinations were trained and submitted to a calibration process to standardize the diagnostic criteria. After a theoretical explanation of the criteria, a calibration exercise was performed with 20 children. Examiners obtained a mean inter-agreement of 0.81 (range 0.75-1.0) in the different occlusion situations assessed, as measured by the Kappa coefficient, a level of agreement considered excellent. During data collection, $5 \%$ of the sample was reexamined to assess the intraexaminer agreement, which was 0.85 .

The visual inspection of the children's oral cavity was performed at the school, under natural light, following WHO biosafety guidelines. The child was accommodated sitting on an ordinary school chair, with his head supported, and facing a natural light source (window). The examiner sat facing the child, and performed the examination using gauze and a millimeter scale (flexible plastic ruler). The student was positioned closely facing the examiner, thus enabling the professional to correctly record the data and properly visualize the different elements of the exam. The data obtained from the clinical oral examination were written down in a dental record.

\section{Ethical aspects}

The project was approved by the Local Human Research Ethics Committee (\# 019-2006), and written informed consent was obtained from the parents or guardians of each participant. Information on the oral health status of the child was sent to the responsible persons when the research was concluded.

\section{Data analysis}

Descriptive analyses were conducted of the variables collected. For analysis purposes, the normal and mild categories were grouped together, since mild alterations refer to minimum alterations, which generally do not require treatment. The relationship between breastfeeding, pacifier use and development of moderate/severe malocclusion was assessed through bivariate and multivariable logistic regression, yielding an odds ratio (OR) and 95\% confidence intervals (95\%CI). The effect modification between pacifier use and breastfeeding on malocclusion was tested in regression models using a joint effect variable (pacifier use*breastfeeding). The association between the joint effect variable and malocclusion was adjusted for demographic and socioeconomic variables. Doubledata entry was conducted, and the data were analyzed using Stata 14.0 statistical software. The results were evaluated at a statistical significance level of $\mathrm{P}<0.05$.

\section{Results}

Of the 502 children assessed, 489 had complete information and were included in the present study. Mean age was $47(S D=11)$ months. More than half of the children $(57.87 \%)$ had used a pacifier, $46.01 \%$ were exclusively breastfed and $24.74 \%$ were never breastfed. Prevalence of moderate/severe malocclusion was 37.83\% (95\% CI 33.52-42.14). Sample distribution according to occlusal status and associated demographic, socioeconomic, and sucking behavior is presented in Table 1.

Table 2 shows the association between the dummy/ joint effect variable of breastfeeding duration and pacifier use with malocclusion, tested using unadjusted and adjusted risk estimates. When the joint effect variable was added to the model, it was significant, suggesting that pacifier use modifies the relationship between breastfeeding and malocclusion.

Unadjusted analysis showed that children who used a pacifier and were never breastfed $(\mathrm{OR}=15.69 ; 95 \% \mathrm{CI}$ 7.73-31.86), who used a pacifier and were not exclusively breastfed (OR $=12.28$; 95\%CI 6.09-24.75), or who used a pacifier and were exclusively breastfed $(\mathrm{OR}=10.43$; 95\%CI 5.16-21-09), showed worse occlusal conditions compared with children who were exclusively breastfed and never used a pacifier $(\mathrm{OR}=1.00)$.

After adjustments for demographic and socioeconomic variables, the interaction of breastfeeding type and pacifier use remained associated with worse occlusal condition. Children who used a pacifier and were never breastfed $(\mathrm{OR}=19.08$; 95\%CI 8.54-42.63), who used a pacifier and were not exclusively breastfed $(\mathrm{OR}=13.74 ; 95 \% \mathrm{CI}$ 6.11-30.92), or who used a pacifier and were exclusively breastfed (OR $=9.87$; 95\%CI 4.42-22.03), had worse occlusal conditions than children who never used a pacifier and were exclusively breastfed $(\mathrm{OR}=1.00)$. 
- Pacifier use modifies the association between breastfeeding and malocclusion: a cross-sectional study

Table 1. Characteristics of the sample and occlusal status in preschool children in Pelotas, RS-Brazil $(\mathrm{n}=489)$.

\begin{tabular}{|c|c|c|c|}
\hline \multirow{2}{*}{ Variable } & \multirow{2}{*}{$\mathrm{n}(\%)^{*}$} & Normal/Mild & Moderate/Severe \\
\hline & & $\mathrm{n}(\%)$ & $\mathrm{n}(\%)$ \\
\hline \multicolumn{4}{|l|}{ Gender } \\
\hline Male & $252(51.53)$ & $152(60.32)$ & $100(39.68)$ \\
\hline Female & 237 (48.47) & $152(64.14)$ & $85(35.86)$ \\
\hline \multicolumn{4}{|l|}{ Mother's age (years)* } \\
\hline $18-26$ & $130(26.86)$ & $73(56.15)$ & $57(43.85)$ \\
\hline $27-36$ & $223(46.07)$ & $146(65.47)$ & 77 (34.53) \\
\hline$>37$ & 131 (27.07) & $82(62.60)$ & $49(37.40)$ \\
\hline \multicolumn{4}{|l|}{ Family income* } \\
\hline $1^{\circ}$ tertile $(0-520)$ & 135 (33.01) & $82(60.74)$ & $53(39.26)$ \\
\hline $2^{\circ}$ tertile $(521-1500)$ & 147 (35.94) & $87(59.18)$ & $60(40.82)$ \\
\hline $3^{\circ}$ tertile (1501-20000) & 127 (31.05) & $87(68.50)$ & $40(31.50)$ \\
\hline \multicolumn{4}{|l|}{ Mother's schooling* } \\
\hline$>8$ years & $92(18.97)$ & $56(60.87)$ & $36(39.13)$ \\
\hline$\leq 8$ years & 393 (81.03) & $245(62.34)$ & $148(37.66)$ \\
\hline \multicolumn{4}{|l|}{ Type of school } \\
\hline Public & 191 (39.06) & 118 (61.78) & $73(38.22)$ \\
\hline Private & $298(60.94)$ & $186(62.42)$ & $112(37.58)$ \\
\hline \multicolumn{4}{|l|}{ Duration of pacifier use* } \\
\hline Never used & $205(42.01)$ & $185(90.24)$ & $20(9.76)$ \\
\hline Used & 283 (57.99) & 119 (42.05) & $164(57.95)$ \\
\hline \multicolumn{4}{|l|}{ Type of breastfeeding } \\
\hline Exclusive breastfeeding & $225(46.01)$ & $162(72.00)$ & $63(28.00)$ \\
\hline Non-exclusive breastfeeding & $143(29.24)$ & $81 \quad(56.64)$ & $62(43.36)$ \\
\hline Never breastfed & $121(24.75)$ & $61(50.41)$ & $60(49.59)$ \\
\hline Total & $489(100.00)$ & $304(62.17)$ & $185(37.83)$ \\
\hline
\end{tabular}

*Sample is lower than 489 due to incomplete information.

Table 2. Unadjusted and adjusted association between breastfeeding and pacifier use with malocclusion. Logistic Regression Analysis ( $\mathrm{n}=489$ ).

\begin{tabular}{lcc}
\hline Breastfeeding and pacifier use & Unadjusted OR (95\%Cl) & Adjusted OR (95\%Cl)* \\
\hline Exclusively breastfed and never used pacifier & 1.00 & 1.00 \\
Not exclusively breastfed and never used pacifier & $1.60(0.60-4.29)$ & $1.25(0.36-4.30)$ \\
Exclusively breastfed and used pacifier & $10.43(5.16-21.09)$ & $9.87(4.42-22.03)$ \\
Not exclusively breastfed and used pacifier & $12.28(6.09-24.75)$ & $13.74(6.11-30.92)$ \\
Never breastfed and used pacifier & $15.69(7.73-31.86)$ & $19.08(8.54-42.63)$ \\
\hline
\end{tabular}

*Adjusted for sex, family income, mother's schooling, type of school and mother's age.

\section{Discussion}

This study was designed to analyze the association of breastfeeding and pacifier use with malocclusion in preschool children. Results confirmed that, when a pacifier is used, the positive effect of breastfeeding on the occlusal status changes, increasing the chance of developing malocclusion regardless of breastfeeding habits. Children who used a pacifier and never breastfed had a greater chance of developing moderate $\backslash$ severe malocclusion. The protective effect of exclusive breastfeeding against malocclusion has been demonstrated. ${ }^{12,13} \mathrm{In}$ addition, previously published studies ${ }^{7,9}$ have shown a significant association between pacifier use and the development of malocclusion. Results confirm that children who were exclusively breastfed for 6 months and never used a pacifier had a lower frequency of moderate/severe malocclusion than other children. This is important, since the identification of factors that exacerbate the development of malocclusion in 
primary teeth can ultimately improve oral health and reduce the impact of these conditions on the quality of life.

Feldens et al. ${ }^{14}$ assessed certain factors associated with distoclusion, a type of malocclusion in the primary dentition, and found that, in the unadjusted model, pacifier use, bottle-feeding and the duration of exclusive breastfeeding were associated with this outcome. After adjustments, bottle-feeding and breastfeeding were no longer statistically significant, suggesting that the associations in the unadjusted model were the result of the confounding effect of pacifier use. That is, children who were breastfed for a shorter period of time or who continued bottle-feeding had a greater likelihood of exhibiting malocclusion, because they used a pacifier longer. Chen et al. ${ }^{15}$ found that the duration of breastfeeding was associated with the prevalence of posterior crossbite, no maxillary space in the deciduous dentition, and also the development of the pacifier-sucking habit.

Thus, there is an intricate relationship among the factors of use of pacifier, breastfeeding and bottle-feeding habits. ${ }^{14}$ Previous studies indicate that breastfeeding can prevent the occurrence of deleterious sucking habits, such as pacifier use, finger sucking, and bottle-feeding, ${ }^{16,17,18}$ and that there is evidence showing that pacifier use in infancy is associated with a shorter duration and non-exclusivity of breastfeeding. ${ }^{6}$ A systematic review, however, found that pacifier use in healthy term breastfeeding infants started at birth or after lactation was established, and did not significantly affect the prevalence or duration of exclusive and non-exclusive breastfeeding up to four months of age. ${ }^{19}$ In addition, benefits have been reported of pacifier use, including the calming effect on the child and the mother, and the reduction in the risk of sudden death. ${ }^{6,20}$ However, there are also reports of the potential risks to the child's heath of using plastic and rubber bottle nipples and pacifiers in relation to developing asthma and allergies. ${ }^{21}$ For this reason, governmental policies that promote healthy behavior, including reducing the use of pacifiers and encouraging breastfeeding, must be adopted and discussed with parents.

Given the benefits of exclusive breastfeeding, it is important to identify the factors that may disrupt this practice and lead to non-exclusive and/or shorter duration breast-feeding. ${ }^{22}$ Thus, it is vital that professionals instruct families on how important breastfeeding is, and how they can avoid or at least reduce the duration of pacifier use.

This study shows that even children who were breastfed (exclusively or non-exclusively) present increased risk of malocclusion if they are exposed to a pacifier. Findings reinforce the importance of preventing harmful oral habits, especially among children who were not breastfed or were breasted for a short period. Malocclusion in the primary dentition may increase the risk of malocclusion in the mixed and permanent dentition. ${ }^{23}$ The upshot is impaired oral health-related quality of life. ${ }^{24}$ The findings of a previous literature review ${ }^{25}$ reinforce the benefits of adopting exclusive breastfeeding practices and avoiding non-nutritive sucking habits to promote harmonic craniofacial growth, with lifelong benefits. In addition, professionals should be aware of the possible consequences of non-nutritive habits, so that they can diagnose and monitor its sequelae, and thus reduce the development of sever malocclusion.

Previous study findings confirm that pacifier use modifies the association between breastfeeding and primary dentition malocclusion. Results show that the protective effect of breastfeeding on malocclusion was nullified by pacifier use among predominantly breastfed children, but not among those who were exclusively breastfed ${ }^{10}$. However, this was the first study to test the association between the dummy/ joint effect variable of breastfeeding and pacifier use with malocclusion, using crude and adjusted estimates. In this respect, its results add to the current knowledge about the benefits of breastfeeding, and strengthen the WHO recommendations of exclusive breastfeeding up to 6 months. ${ }^{26}$

Among the limitations of this study is its crosssectional design, which presents some intrinsic limitations. The memory bias of the mothers could affect the accuracy of the reports of feeding practice duration, and thus influence its results. However, it is unlikely that memory bias could influence the associations found, since the parents were unaware of the malocclusion status of their children, or the possible influence of breastfeeding on occlusal 
traits. The questionnaire used was previously tested, and alterations were made to enhance its comprehension. However, the measures were not validated. In addition, the effect of heredity and certain detrimental oral habits on malocclusion were not included in the questionnaire. Thus, prospective studies of correlated determinants of malocclusions should be conducted. Furthermore, the data collection is relatively old. However, there is a plausible mechanism which links the conditions assessed in this study, associating pacifier use and breastfeeding with malocclusion, and which is unlikely to change over time.

\section{References}

1. Callaghan A, Kendall G, Lock C, Mahony A, Payne J, Verrier L. Association between pacifier use and breastfeeding, sudden infant death syndrome, infection and dental malocclusion. Int J Evid Based Healthc. 2005 Jul;3(6):147-67. https://doi.org/10.1111/j.1479-6988.2005.00024.x

2. Alm B, Wennergren G, M?llborg P, Lagercrantz $H$. Breastfeeding and dummy use have a protective effect on sudden infant death syndrome. Acta Paediatrica (Oslo, Norway : 1992). 2016;105(1):31-8. https://doi.org/10.1111/apa.13124

3. Howard CR, Howard FM, Lanphear B, Eberly S, Blieck $E A$, Oakes $D$ et al. Randomized clinical trial of pacifier use and bottle-feeding or cupfeeding and their effect on breastfeeding. Pediatrics. 2003 Mar;111(3):511-8. https://doi.org/10.1542/peds.111.3.511

4. Boccolini CS, Carvalho ML, Oliveira MI. Factors associated with exclusive breastfeeding in the first six months of life in Brazil: a systematic review. Rev Saude Publica. 2015;49(0):49. https://doi.org/10.1590/S0034-8910.2015049005971

5. Buccini GD, Pérez-Escamilla R, Venancio SI. PérezEscamilla R, Venancio SI. Pacifier use and exclusive breastfeeding in Brazil. J Hum Lact. 2016;32(3):NP52-60. https://doi.org/10.1177/0890334415609611

6. Agarwal SS, Nehra K, Sharma M, Jayan B, Poonia A, Bhattal $\mathrm{H}$. Association between breastfeeding duration, non-nutritive sucking habits and dental arch dimensions in deciduous dentition: a cross-sectional study. Prog Orthod. 2014 Oct;15(1):59. https://doi.org/10.1186/s40510-014-0059-4

7. Romero CC, Scavone-Junior H, Garib DG, Cotrim-Ferreira FA, Ferreira RI. Breastfeeding and non-nutritive sucking patterns related to the prevalence of anterior open bite in primary dentition. J Appl Oral Sci. 2011 Apr;19(2):161-8. https://doi.org/10.1590/S1678-77572011000200013

\section{Conclusion}

The findings of this cross-section study reinforce the detrimental effects of pacifier use on occlusal status, even when practicing breastfeeding. Thus, it can be concluded that pacifier use may modify the relationship between breastfeeding and occlusal status, confirming the hypothesis tested in this study.

\section{Acknowledgment}

The authors would like to thank Dr. Dione Dias Torriani (in memoriam) for her commitment to the present research.

8. Melink S, Vagner MV, Hocevar-Boltezar I, Ovsenik M. Posterior crossbite in the deciduous dentition period, its relation with sucking habits, irregular orofacial functions, and otolaryngological findings. Am J Orthod Dentofacial Orthop.. 2010;138(1):32-40. https://doi.org/10.1016/j.ajodo.2008.09.029

9. Costa CT. Estudo das características da oclusão na dentição decídua e na mista e fatores associados [thesis]. Pelotas: Universidade Federal de Pelotas, 2013. 10. World Health Organization - WHO. Oral health surveys: basic methods. 3rd ed. Geneva: World Health Organization; 1987.

10. Rochelle IM, Tagliaferro EP, Pereira AC, Meneghim MD. Nóbilo KA, Ambrosano GMB. Breastfeeding, deleterious oral habits and malocclusion in 5-year-old children in São Pedro, SP, Brazil. Dental Press J Orthod. 2010;15(2):71-81. https://doi.org/10.1590/S2176-94512010000200010

11. Peres KG, Cascaes AM, Peres MA, Demarco FF, Santos IS, Matijasevich A et al. Exclusive breastfeeding and risk of dental malocclusion. Pediatrics. 2015 Jul;136(1):e60-7. https://doi.org/10.1542/peds.2014-3276

12. Peres KG, Cascaes AM, Nascimento GG, Victora CG. Effect of breastfeeding on malocclusions: A systematic review and meta-analysis. Acta Paediatrica (Oslo, Norway : 1992). 2015;104(467):54-61. https://doi.org/10.1111/apa.13103

13. Feldens CA, Martins RP, Maciel RR, Vargas-Ferreira $F$, Kramer PF. Factors associated with the occurrence of distoclusion in the primary dentition: a hierarchical analysis. J Clin Pediatr Dent. 2016;40(1):88-93. https://doi.org/10.17796/1053-4628-40.1.88

14. Chen X, Xia B, Ge L. Effects of breast-feeding duration, bottle-feeding duration and non-nutritive sucking habits on the occlusal characteristics of primary dentition. BMC Pediatr. 2015 Apr;15(1):46. https://doi.org/10.1186/s12887-015-0364-1 
15. Roscoe MG, Bonifacio SVS, da Silva TB, Pingueiro JM, Lemos MM, Feres MF. Association of breastfeeding duration, nonnutritive sucking habits, and malocclusion. Int J Clin Pediatr Dent. 2018 Jan-Feb;11(1):18-22. https://doi.org/10.5005/ip-journals-10005-1477

16. Pizzol KE, Montanha SD, Fazan ET, Boeck EM, Rastelli AN. Prevalence of nonnutritive sucking habits and their relationship to age, gender and type of feeding in preschool children from Araraquara-Brazil. Rev CEFAC. 2012;14(3):506-15. https://doi.org/10.1590/S1516-18462012005000001

17. Moimaz SA, Garbin AJ, Lima AM, Lolli LF, Saliba O, Garbin CA. Longitudinal study of habits leading to malocclusion development in childhood. BMC Oral Health. 2014 Aug;14(1):96. https://doi.org/10.1186/1472-6831-14-96

18. Jaafar SH, Ho JJ, Jahanfar S, Angolkar M. Effect of restricted pacifier use in breastfeeding term infants for increasing duration of breastfeeding. Cochrane Database Syst Rev. 2016 Aug;8(8):CD007202. https://doi.org/10.1002/14651858.CD007202.pub4

19. Salone LR, Vann WF, Dee DL. Breastfeeding: An overview of oral and general health benefits. J Am Dent Assoc. 2013;144(2):143-51.

20. Hsu NY, Wu PC, Bornehag CG, Sundell J, Su HJ. Feeding bottles usage and the prevalence of childhood allergy and asthma. Clin Dev Immunol. 2012;2012:158248. https://doi.org/10.1155/2012/158248
21. Azzeh FS, Alazzeh AY, Hijazi HH, Wazzan HY, Jawharii MT, Jazar AS et al. Factors associated with not breastfeeding and delaying the early initiation of breastfeeding in Mecca Region, Saudi Arabia. Children (Basel). 2018 Jan;5(1):E8. https://doi.org/10.3390/children5010008

22. Peres KG, Peres MA, Thomson WM, Broadbent J, Hallal PC, Menezes AB. Deciduous-dentition malocclusion predicts orthodontic treatment needs later: findings from a population-based birth cohort study. Am J Orthod Dentofacial Orthop. 2015;147(4):492-8. https://doi.org/10.1016/i.ajodo.2014.12.019

23. Simões RC, Goettems ML, Schuch HS, Torriani DD, Demarco FF. Sim? es RC, Goettems ML, Schuch HS, Torriani DD, Demarco FF. Impact of malocclusion on oral healthrelated quality of life of 8-12 years old schoolchildren in Southern Brazil. Braz Dent J. 2017 Jan-Feb;28(1):105-12. https://doi.org/10.1590/0103-6440201701278

24. Thomaz EB, Alves CM, Gomes E, Silva LF, Almeida CCCR, Britto ES et al. Breastfeeding versus bottle feeding on malocclusion in children: a meta-analysis study. J Hum Lact. 2018 Mar:890334418755689. https://doi.org/10.1177/0890334418755689

25. World Health Organization, United Nations Children's Fund. Global strategy for infant and young child feeding. Geneva: World Health Organization; 2003. 